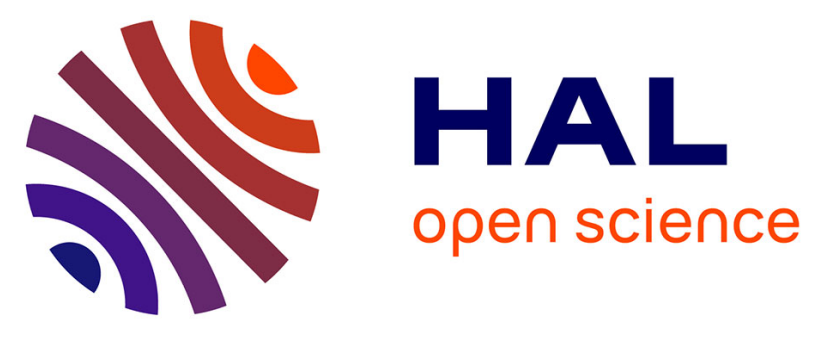

\title{
Advances in mass spectrometry for iron speciation in plants
}

\author{
Ghaya Alchoubassi, Justyna Aszyk, Paulina Pisarek, Katarzyna Bierla, \\ Laurent Ouerdane, Joanna Szpunar, Ryszard Lobinski
}

\section{To cite this version:}

Ghaya Alchoubassi, Justyna Aszyk, Paulina Pisarek, Katarzyna Bierla, Laurent Ouerdane, et al.. Advances in mass spectrometry for iron speciation in plants. Trends in Analytical Chemistry, 2018, 104, pp.77-86. 10.1016/j.trac.2017.11.006 . hal-03133526

\section{HAL Id: hal-03133526 \\ https://hal.science/hal-03133526}

Submitted on 6 Feb 2021

HAL is a multi-disciplinary open access archive for the deposit and dissemination of scientific research documents, whether they are published or not. The documents may come from teaching and research institutions in France or abroad, or from public or private research centers.
L'archive ouverte pluridisciplinaire HAL, est destinée au dépôt et à la diffusion de documents scientifiques de niveau recherche, publiés ou non, émanant des établissements d'enseignement et de recherche français ou étrangers, des laboratoires publics ou privés. 


\title{
Advances in mass spectrometry for iron speciation in plants
}

\author{
Ghaya AlChoubassi a, Justyna Aszyk ${ }^{\text {a, b }}$, Paulina Pisarek ${ }^{\text {a, c }}$, Katarzyna Bierla ${ }^{\text {a }}$ \\ Laurent Ouerdane ${ }^{a}$, Joanna Szpunar ${ }^{\text {a, }}$, Ryszard Lobinski ${ }^{\text {a, c }}$ \\ ${ }^{a}$ Institute of Analytical Sciences, IPREM, UMR 5254 CNRS-UPPA, Hélioparc, Pau, France \\ b Department of Analytical Chemistry, Faculty of Chemistry, Gdańsk University of Technology, 11/12 Narutowicza Str, Gdańsk, Poland \\ ${ }^{\mathrm{c}}$ Department of Analytical Chemistry, Warsaw University of Technology, Noakowskiego 3, 00-664, Warsaw, Poland
}

\section{A R T I C L E I N F O}

\section{Article history:}

Available online $\mathrm{xxx}$

\section{Keywords:}

Iron Speciation

$\mathrm{X}$ ray spectroscopy

Liquid chromatography

ICP MS

Electrospray mass spectrometry

Isotope dilution

\begin{abstract}
A B S T R A C T
Iron is an important nutrient essential for plants and critical for human health. The state-of-the art of methods for iron speciation in cereal grains and plant fluids is critically reviewed. Particular attention is given to the latest developments in the coupling of HPLC with the parallel ICP MS and electrospray ionization (ESI) MS/MS detection, usually QTOF MS or Q-Orbitrap MS, for the identification and quantification of iron species. The coupled techniques allow the direct microanalysis of plant intracellular fluids (xylem and phloem) and complement X-ray absorption spectroscopy (XANES and EXAFS). The increasing resolution and sensitivity of electrospray mass spectrometers and emergence of software allowing extraction of iron specific data from large chromatographic data sets are responsible for the growing role of electrospray MS/MS in speciation studies. The use of stable isotopes for the probing of the reactivity and stability of endogenous metal complexes and quantitative analysis are rising in importance.
\end{abstract}

(C) 2017 Elsevier B.V. All rights reserved.

\section{Introduction}

Iron deficiency anemia which is a consequence of inadequate dietary intake and low bioavailability of iron affects ca. $30 \%$ of the world's population [1]. It produces serious adverse health effects with socioeconomic implications and combating it has been considered as one of the 10 major challenges faced by the mankind [1]. The core of the problem is the unfavorable iron speciation: relatively low levels of non-heme iron and high levels of dietary factors, such as e.g. phytic acid, which inhibit human iron absorption in stable food crops [2].

The challenges driving research in iron speciation in plants include the understanding of the mechanisms governing the uptake of iron from soil, its transport to aboveground plant tissues and storage, and of the mechanisms of the bioavailability of Fe from staple food, such as wheat, beans, barley, or maize [3,4]. The iron concentrations reported in studies of edible grains varied between 15 and $115 \mu \mathrm{g} / \mathrm{g}$ [3-7]. Higher plants have developed two distinct strategies to acquire iron, which is only slightly soluble in soil, from the rhizosphere: (i) the reduction strategy where Fe(III) is reduced to $\mathrm{Fe}(\mathrm{II})$ which can then be transported into the root epidermal cells by the divalent metal transporters and (ii) the chelation strategy

\footnotetext{
* Corresponding author.

E-mail address: joanna.szpunar@univ-pau.fr (J. Szpunar).
}

where $\mathrm{Fe}(\mathrm{III})$ is complexed by soluble phytosiderophores (PS) induced upon iron deficiency and released from the root epidermis, the resulting Fe (III)-PS complexes are readily transported back into the roots $[8,9]$. Coumarins were recently discovered to play an important role in Fe acquisition from soil for plants [10,11]. However, the actual formation of a Fe-coumarin metal complex in root exudate seems not to have been confirmed yet. As a consequence, the direct role (by complexation) of coumarins in iron uptake [and not only by reduction of $\mathrm{Fe}(\mathrm{III})]$ cannot be proved. Chelating ability was found in an in vitro model study for the coumarins with 2hydroxyl groups in ortho position, but not for those with single hydroxyl groups [12]. In a recent review the need to carry out much more work was postulated to fully understand the strong beneficial effect of coumarin secretion on Fe acquisition under alkaline conditions, both biochemically and physiologically [10].

The understanding of the iron metabolism which is critically dependent on the fine knowledge of its speciation may facilitate genetic engineering in order to increase the iron content in the required chemical form (and in a specific plant organ) in the context of human nutrition or environmental clean-up by phytoremediation [13] ( $c f$. the case of the recent red mud flooding in Brazil [14]). Hyperaccumulation of iron is achieved through coordination of several processes, including enhanced metal uptake (assisted by secretion of siderophores), efficient root-to-shoot translocation and effective detoxification in leaves [15]. An additional important 
factor in the context of biofortification is the translocation of iron into (edible) grains.

Iron in plants occurs in two principal oxidation states Fe(II) and $\mathrm{Fe}(\mathrm{III})$ and in a variety of complexes of different stability. The most popular ligands complexing iron in plants are summarized in Fig. 1. The compounds of interest in speciation studies include: (i) soluble complexes with organic acids (ferric and ferrous citrates, mixed citrate-malates, aspargates), (ii) siderophores - high-affinity $\mathrm{Fe}(\mathrm{III})$ chelating compounds derived from nicotianamine: mugineic acid, 3-hydroxymugineic acid, 2'-deoxymugineic acid, avenic acid, and distichonic acid, (iii) phytate (myo-inositol-1,2,3,4,5,6hexakis-phosphate: IP6), both soluble and insoluble, and (iv) iron-binding proteins, especially ferritin. In some cases, e.g., citrate, both (ferric and ferrous) ions are able to form complexes with the same ligand and the formation of mixed-ligand complexes (e.g., citrate-malate $[16,17]$ ) is common. Metal, including iron, species involved in long distance metal transport in plants have been reviewed [18]. A special interest was focused on ferritin due to its putative role in iron bioavailability from food plants whereas some other proteins have been identified in specific plant physiology projects [19].

Originally, iron speciation analysis was (i) limited to the discrimination of $\mathrm{Fe}(\mathrm{II})$ and $\mathrm{Fe}(\mathrm{III})$ which is readily achieved by XANES, (ii) based on the isolation of a particulate fraction, such as phytates or ferritin, for its further characterization by spectroscopic methods, and (iii) based on calculation methods determining the distribution amongst the most abundant species. The introduction of electrospray MS allowed the identification of several citrate complexes but direct ESI MS studies of plant extracts or plant fluids have been scarce $[16,17,20]$. The advent of HPLC with iron-specific detection, usually by ICP MS, allowed the detection of specific fractions of water soluble complexes which could be identified with more or less success by electrospray MS. A significant part of iron in plants occurs as water insoluble species and needs to be solubilized before analysis by HPLC-based techniques; it is associated with a serious risk of species loss and/or transformation.

This manuscript critically evaluates the advantages and limitations of methods of iron speciation in plants and highlights the current trends in this area. Particular attention is given to the advances in chromatography with mass spectrometric detection by ICP MS and/or high-resolution electrospray MS/MS (e.g. QTOF MS or Q-Orbitrap MS). Correct isotopic patterns can only be observed if there are no isobaric compounds co-eluting. Isobaric interferences are much more likely to occur at nominal resolution than at high resolution, and commonplace in the analysis of biological samples. This is especially critical for low concentrated iron complexes, where isobaric interferences can lead to false positive or false negative detection of Fe complexes. High resolution is critical to distinguish metal complexes from other randomly occurring organic molecules. Also - if doubts subsist because of the low intensity of signals and numerous interfering molecules or salts high resolution spectra of molecule fragments (MS/MS) can confirm or invalidate hypotheses of the presence of the Fe complex. The high resolution MS also offers new opportunities for exploiting the potential of stable isotopes for the probing of the stability and reactivity of iron species and their quantitative determination (in the MRM or SRM mode, for Q-TOF or Q-Orbitrap mass spectrometers).

\section{Siderophores}<smiles>N[C@H](CC[C@H](CCCN1CC[C@H]1CO)C(=O)O)C(=O)O</smiles><smiles>O=C(O)C(O)CCN[C@H](C(=O)O)[C@@H](O)CN1CC[C@H]1C(=O)O</smiles>

mugineic acid

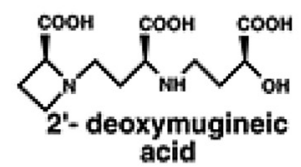

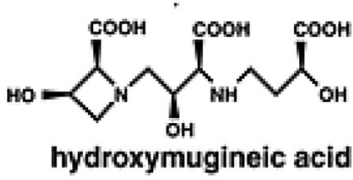<smiles>O=C(O)C(O)CCN[C@H](CCC[C@H](CCCO)C(=O)O)C(=O)O</smiles>

avenic acid $\mathbf{A}$

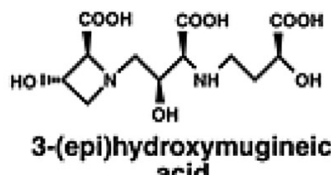
acid

\section{Organic Acids}<smiles>NC(=O)CC[C@H](N)C(=O)O</smiles>

glutamic acid<smiles>O=C(O)CC(O)(CC(=O)O)C(=O)O</smiles>

citric acid<smiles>O=C(O)CC(O)C(=O)O</smiles>

malic acid<smiles>NC(CC(=O)O)C(=O)O</smiles>

aspartic Acid

\section{Phytate}

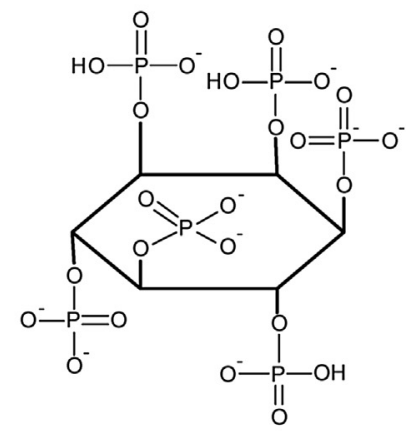

Fig. 1. Principal iron-complexing ligands in plants. 


\section{Direct analysis by X-ray spectroscopy}

X-ray spectroscopy (XAS) provides information on the oxidation state and immediate coordination environment of iron present in the sample. The X-ray absorption near-edge structure (XANES) region of XAS spectra is sensitive to the oxidation state and coordination environment whereas the EXAFS (Extended X-ray Absorption Fine Structure) region is characteristic (coordination number and interatomic distances) of the local atomic structure surrounding an iron atom.

Edible grains (staple food) of wheat, rice, beans can be analyzed by XAS as such fixed on a holder [21] but the use of thin sections was recommended to reduce the distortion of the signal [22]. XAS has long been considered as a "direct" technique eliminating the risk of changes in speciation during sample preparation and irradiation. However, grinding and analysis of pellets was found to provoke oxidation [21]. Also, several Fe(III) complexes, e.g. succinate, nicotianamine, and $\alpha$-ketoglutarate were found not to be stable in the synchrotron beam [23].
The XAS spectra (example in Fig. 2) are analyzed by linear combination fitting (LCF) using the spectra of standard compounds. This implies the need for prediction of the existence of some species and the availability of the corresponding standards. The sets of standards used in the two recent studies included (i) Fe(II) glutathione, Fe(II) sulphate, Fe(II) phytate, Fe(II) oxalate, Fe(III) phytate, $\mathrm{Fe}(\mathrm{III})$ sulphate, $\mathrm{Fe}(\mathrm{III})$ citrate, $\mathrm{Fe}(\mathrm{III})$ phosphate, and $\mathrm{Fe}_{3} \mathrm{O}_{4}, \alpha$ $\mathrm{FeOOH}$, and $\mathrm{Fe}_{2} \mathrm{O}_{3}[21]$, or (ii) citrate, $\alpha$-ketoglutarate, acetate, fumarate, succinate, malate, shikimate, and nicotianamine complex [23].

XAS analysis can be used to indicate the relative amount of major species in the samples [21,23-25] with precisions below 5\% for binary systems, such as e.g. Fe(II)/Fe(III) [21] or iron phytate/ citrate [15]. An unmatched advantage of XAS is the consideration of insoluble Fe complexes. It turned out to be useful in the evaluation of the phytate/citrate ratio in modified and control aleurone cells of wheat grains (Triticum aestivum L.) [24]. The performance of XAS degrades for systems with several intervening ligands, especially at largely different concentrations. The precision of spectra is a

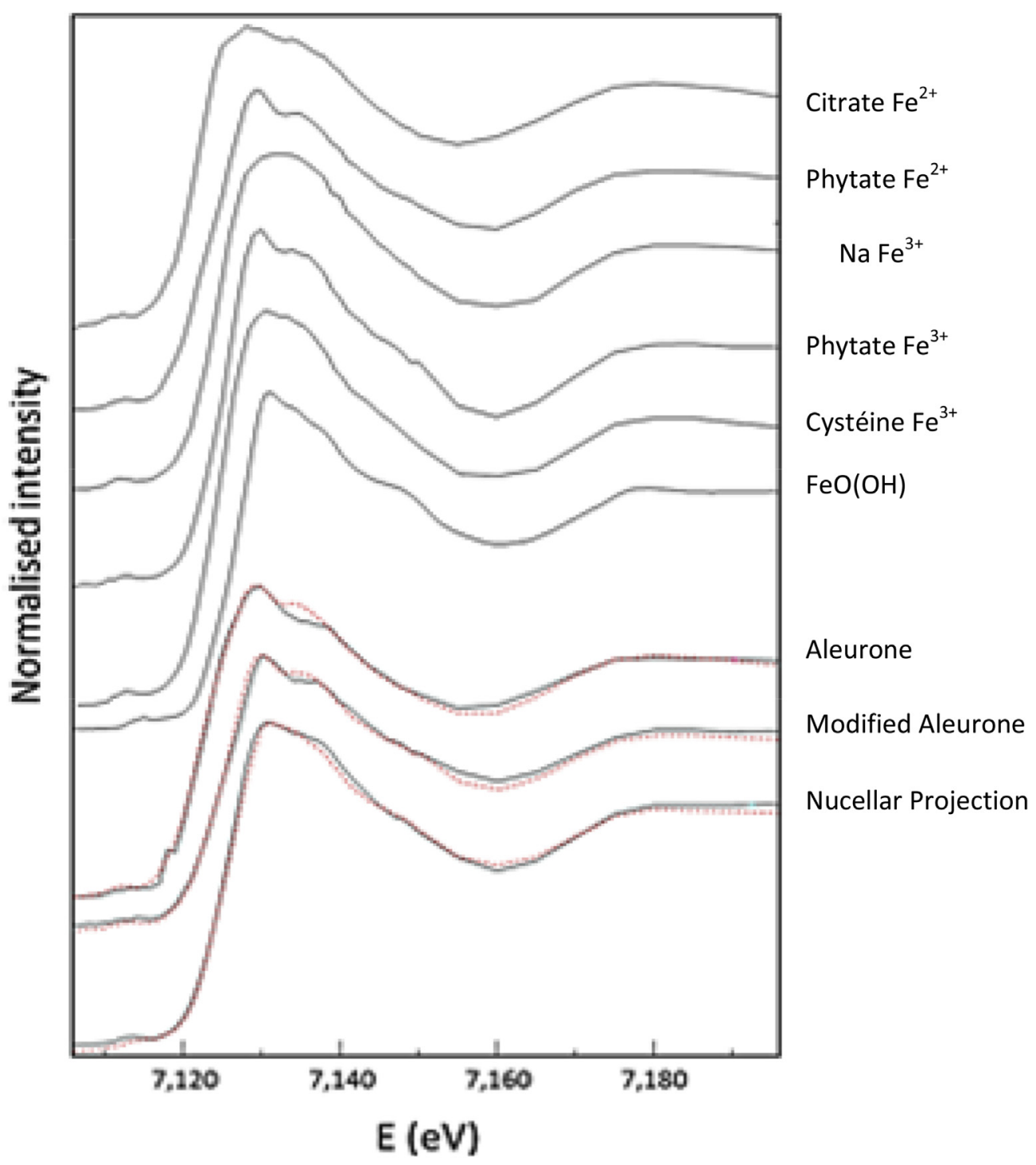

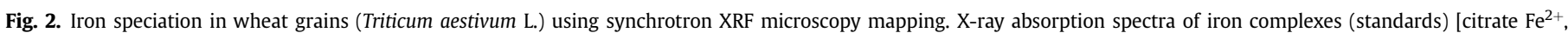
phytate $\mathrm{Fe}^{2+}$, nicotianamine (NA) $\mathrm{Fe}^{3+}$, phytate $\mathrm{Fe}^{3+}$, cysteine $\mathrm{Fe}^{3+}, \mathrm{FeO}(\mathrm{OH})$ ] and wheat grain sections. The dotted lines give the linear combination fitting results [24]. 
function of irradiation time which is set off by the risk of radiation damage of the analyte [23]. Also, the a priori knowledge of the ligands is indispensable.

XAS provided valuable hints on the oxidation state and immediate coordination region of iron, e.g. Fe-O-P-R and Fe-O-S-R [21]. Octahedral coordination by six oxygen atoms and two phosphorous atoms was observed in wheat $[16,25]$. Complementary information was obtained by chromatographic techniques upon extraction of water soluble species, but observed extraction yields were low $[7,26]$. An advantage of XAS is the possibility of speciation studies at high spatial resolution (e.g. in a leaf vein) [27].

The principal limitation of X-ray absorption techniques is the detection limit; the identification of a Fe complex requires iron concentration at the ppm levels. The evolution of XAS goes towards the use of high brilliance sources which, on one hand, decreases the detection limits down to sub-ppm levels, but, on the other hand, increases the risk of radiation damage to the analyte [23]. An analyses of xylem sap samples revealed $\mathrm{Fe}(\mathrm{III})$ to be complexed by citrate and acetate; the presence of $\mathrm{Fe}(0)$ in one of the samples was considered to be an artifact created by sample irradiation with high intensity synchrotron X-rays [23].

\section{Liquid phase separation techniques for iron complexes in plants}

The limitations of XAS (need for simple systems with a restricted number of already known ligands and relatively high iron concentrations) can be overcome by chromatography with either ICP or ESI MS detection. It is particularly true for plant sap, where the $\mathrm{Fe}$ concentrations in the low ppm range make speciation analysis challenging. The meaningful use of coupled techniques raises a number of questions related to sample preparation, species stability, artifact formation, separation efficiency, and column recovery and mobile phase compatibility with the detection techniques. The limitations differ for ICP MS and ESI MS which requires both techniques to be used for the internal validation of the results and elimination of analytical artefacts.

\subsection{Sample preparation}

Ideally, the speciation analysis should be carried out without sample preparation which favors the analysis of plant fluids, such as xylem, phloem or root exudates. The steady increase in the sensitivity of MS methods is likely to make the direct analysis of picoliter volumes of individual cells using on-chip chromatography possible in near future.

A common sampling method is cutting of the plant top with a razor blade, allowing the stumps to bleed for a few minutes, and fitting then the stem with plastic tubing for xylem sap recovery [28]. An interesting approach was the use of a brown plant hopper in a controlled environment (temperature, humidity, light exposure) conditions to suck out rice phloem sap [29]. The stylets of the insect were subsequently cut by a YAG laser and the exudated phloem sap ( $\mathrm{pH} \mathrm{8}$ ) was collected in microcapillary tubes [29].

The two major risks concern (i) dissociation of iron complexes and (ii) oxidation of $\mathrm{Fe}(\mathrm{II})$ to $\mathrm{Fe}(\mathrm{III})$. Drying of samples may lead to iron precipitation and destruction of complexes so lyophilisation should be avoided. Care should be taken to collect samples under N2 or Ar flushing; samples should be either analyzed promptly or frozen immediately after collection in liquid nitrogen [and kept frozen until analysis to prevent the oxidation of $\mathrm{Fe}(\mathrm{II})]$. The use of fluorescent probes can help monitor Fe(II) concentration but they account for "free iron" or "labile iron" only and not iron-containing species [30]. The addition of isotopically enriched $\mathrm{Fe}(\mathrm{II})$ to the sample can help to follow the fate of this ion if doubts exist about its stability. However, it has to be kept in mind that molecules present in the plant matrix could lead to the oxidation of the added $\mathrm{Fe}(\mathrm{II})$ so this method seems to be more adapted to follow long term degradation during storage.

Regarding solid samples, plant leaves can be frozen in liquid $\mathrm{N}_{2}$, homogenized in a ball mill or in a mortar, centrifuged, and filtered using a $0.22-\mu \mathrm{m}$ filter. Grain water extracts (wholemeal wheat flour, bran, subaleurone layer, and endosperm) were obtained by incubation at $37^{\circ} \mathrm{C}$ for $18 \mathrm{~h}$ Tris- $\mathrm{HCl}$ with shaking, centrifugation and $0.32-\mu \mathrm{m}$ filtration. Despite the use of fairly high temperature, the species detected do not seem to be products of enzymatic (or other) degradation of higher MW complexes. The above procedures were focused on the species which were the easiest to mobilize $[3,7,26]$. However, it should be kept in mind that solubilization of iron species from solid samples bears a risk of the degradation and transformation (ligand exchange).

Ideally, various sample preparations should be tested to see if consistent speciation analysis results are obtained. The sample should not be altered or mixed with anything else. However, if there is such a need, care should be taken not to add any compounds that would alter Fe speciation: $\mathrm{pH}$ should be kept similar to sample $\mathrm{pH}$ while potentially chelating molecules and excessive amount of salt or oxidizing/reducing agents should be avoided.

\subsection{Coupled techniques for the analysis for Fe-compounds in plant extracts and fluids}

\subsubsection{Size-exclusion liquid chromatography}

Size-exclusion LC allows the fractionation of iron complexes in plant fluids (xylem and phloem) [31] and plant tissue extracts $[3,4,7,26]$ according to the molecular mass (more precisely, hydrodynamic volume) while iron or its complexes can be specifically monitored using ICP MS or ESI MS, respectively. It has been a method of choice while working with unstable metal complexes in plants as this method is often able to preserve species degraded while other separation mechanisms are used [16,32,33]. The resolution is relatively poor but a high molecular fraction at the (or close to) exclusion volume, a low molecular fraction corresponding to complexes with organic acids and siderophores and - inbetween - soluble phytate fraction can be discriminated [3] (Fig. 3). Its accepted applications include (i) the determination of the apparent molecular mass of well separated compounds, such as e.g. Fe-phytate complex (12.3 kDa) [7], (ii) the isolation of iron complexes for further purification [7], and (iii) the monitoring of the reactivity of iron fractions towards specific enzymes, e.g. that of phytate-Fe complex with phytase, the enzyme responsible for successive dephosphorylation of $\mathrm{IP}_{6}$ [7].

SEC usually requires fairly concentrated salt-rich buffers to minimize the interactions of the analytes with the stationary phase to prevent those which can lead to the dissociation of the complexes present. An interesting trend is the optimization of the choice of the stationary phase and the mobile phase conditions with dilute buffers of weak buffering capacity (i.e., $10 \mathrm{mM}$ ammonium acetate). At these conditions low molecular iron complexes can be separated from each other with the resolution of a single organic acid ligand, e.g. mixed maic/citric complexes [16] (Fig. 4a). Another advantage is the compatibility of such eluents with electrospray ionization allowing the on-line identification of the metal complexes [16]. The advent of more robust electrospray ionization sources and more sensitive mass spectrometers have made a successful coupling of SEC with electrospray MS possible [16]. The SECESI MS coupling allowed the identification of iron nicotianamine, $2^{\prime}$-deoxymugineic acid and mugineic acid complexes in soybean xylem sap [31]. The Fe(III)-2'-deoxymugineic acid complex was 


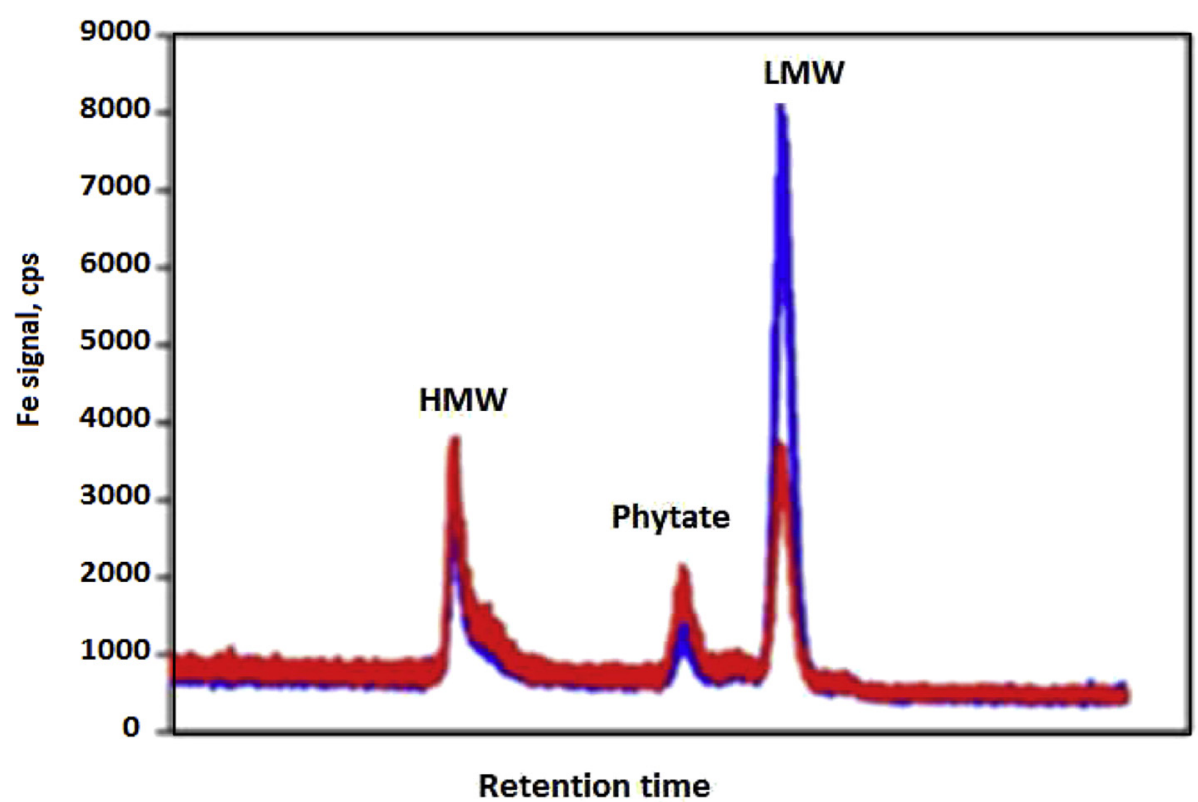

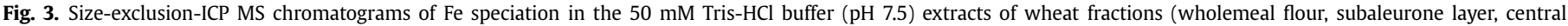
endosperm, and core endosperm) [3] (see text for peak indentification).
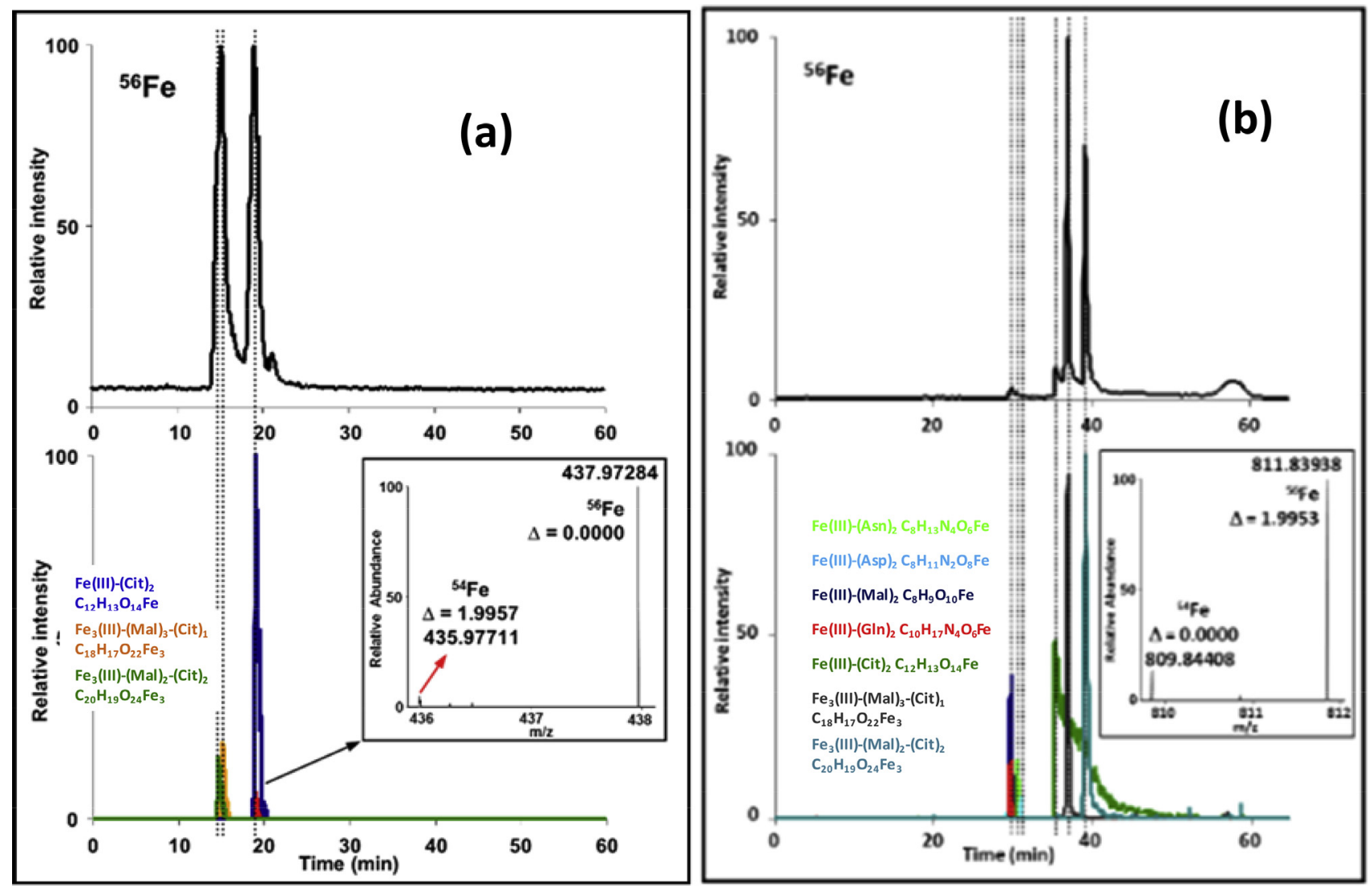

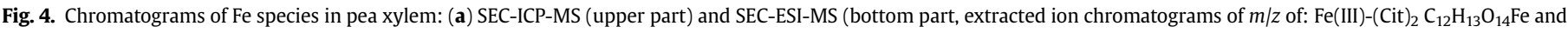

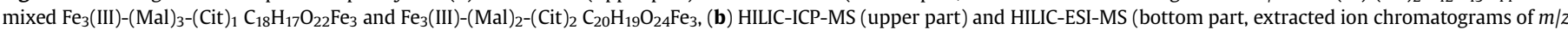

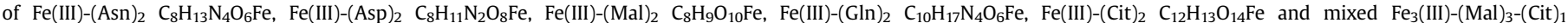
$\mathrm{C}_{18} \mathrm{H}_{17} \mathrm{O}_{22} \mathrm{Fe}_{3}, \mathrm{Fe}_{3}(\mathrm{III})-(\mathrm{Mal})_{2}-(\mathrm{Cit})_{2} \mathrm{C}_{20} \mathrm{H}_{19} \mathrm{O}_{24} \mathrm{Fe}_{3}$. The insets depict zooms of part of mass spectra containing ions with characteristic Fe isotopic signature [16]. 
identified in phloem sap from rice by SEC with off-line ICP MS detection followed by ESI- time-of-flight (TOF) MS [29].

\subsubsection{Hydrophilic interaction ion chromatography (HILIC)}

Hydrophilic interaction chromatography (HILIC) is based on liquid-liquid partition where analytes elute in order of increasing polarity; it provides therefore an approach to efficiently separate small polar compounds on polar stationary phases [34]. Several types of stationary phases are available for HILIC separations. They differ in terms of their chemical functionalities which confer various interaction patterns and, consequently, result in very different selectivities and orders of elution [35].

The coupling of HILIC with ESI - TOF MS (canonical in metabolomics $[36,37]$ ) allowed the detection of whole range of carboxylates in the plant tissue extracts and fluids including oxalic, 2oxoglutaric, cis-aconitic, malic, quinic, shikimic, fumaric, formic, and metaphosphoric (MPA), (succinic citric and ascorbic acids) [38]. The analysis for metal complexes is more challenging as it requires a careful optimization of the ionization mode and the separation of the metal-ligand complex from the excess of the free ligand which could interfere in the ESI process [20]. Both citrate and Fe-citrate complexes are highly polar and there is a consensus on the choice of a zwitterionic hydrophilic interaction stationary phase (ZICHILIC) for their separation $[37,39,40]$. The identification is carried out on the basis of the molecular mass and fragmentation patterns.

An important restriction in the optimization of the separation conditions is the need to maintain the original $\mathrm{pH}$ of the sample during chromatography in order to preserve the metal-ligand equilibria. Addition of organic solvent (usually acetonitrile or methanol) to the eluent (so to the sample) when HILIC is used can change Fe speciation because of the lower solubility of some compounds potentially associated to Fe. In particular, an addition of acetonitrile to aqueous samples leads to the precipitation of most proteins ( $>10 \mathrm{kDa}$ ). Therefore, the use of HILIC should be limited to studies of small $(<10 \mathrm{kDa})$ iron complexes. Samples should be analyzed as soon as they are mixed with the solvent to limit potential loss of Fe species. To ascertain that no changes occurred, an analysis of the water extract by SEC should ideally confirm the presence of Fe complexes. The on-column precipitation should be controlled by checking the elution yield (recovery). The stability of metal-PS complexes during the HILIC separation was investigated [41]. A risk of on-column dissociation and $\mathrm{Fe}(\mathrm{II})$ oxidation was identified. It may cause column contamination, poorly reproducible retention times and lead to systematic errors in the analysis of plant samples so a column cleaning procedure using a $20 \mu \mathrm{M}$ EDTA solution was proposed [41].

HILIC can be readily combined with ICP MS and ESI MS and several authors used both detection modes in parallel combining the iron-specific detection and the identification of the complexes present $[16,17,20]$. A considerable success, stimulated by an early work of Weber et al. [42], concerned the identification of iron phytosiderophores (PSs). The speciation of iron-PSs complexes is critical for understanding the biological functions of different PSs. Direct HPLC - ESI TOF-MS allowed the identification of deoxymugineic acid (DMA), mugineic acid (MA) and epihydroxymugineic acid (epi-HMA), avenic acid (AVA) and hydroxyavenic acid (HAVA), and their ferric complexes in root exudates under iron (Fe) deficiency; however no quantitative information was provided [40]. The high selectivity of a mixed-mode stationary phase allowed the baseline separation of the two Fe-MA diastereomers [39]. The limit of detection was $50 \mathrm{nM}$ for Fe(III)-DMA [39].

HILIC - ESI MS (Fig. 4b) allowed the identification of a number of species with different ligands including: $\mathrm{Fe}(\mathrm{III})-(\mathrm{Asn})_{2}, \mathrm{Fe}(\mathrm{III})-$ $(\text { Asp })_{2}, \mathrm{Fe}(\mathrm{III})-(\mathrm{Mal})_{2}, \mathrm{Fe}(\mathrm{III})-(\mathrm{Gln})_{2}, \mathrm{Fe}(\mathrm{III})-(\mathrm{Cit})_{2}$ and mixed $\mathrm{Fe}_{3}(\mathrm{III})-$ $(\mathrm{Mal})_{3}-\mathrm{Cit}, \mathrm{Fe}_{3}(\mathrm{III})-(\mathrm{Mal})_{2}-(\mathrm{Cit})_{2}, \mathrm{Fe}_{3}$ (III)-Mal-(Cit) $)_{3}$ in pea xylem, although the presence of some of them was not confirmed by the parallel SEC-ESI MS analysis [16].

HILIC ESI MS has largely contributed to the understanding of the role of citrate [20] and citrate-malate complexes [16,17] in iron transport and metabolism. The iron citrate complex which is of high biological relevance shows relatively poor thermodynamical stability. A method to separate and identify Fe-Cit complexes was developed by analyzing $\mathrm{Fe}-\mathrm{Cit}$ solutions at various Fe and Cit concentrations, Fe:Cit ratios and $\mathrm{pH}$ values (5.5) typical of xylem sap, using HPLC with dual ESI-TOFMS and post-column ID ICP-MS detection [20]. Among the complexes found in pea xylem [16] a special attention was paid to the mixed-ligand complexes $\mathrm{Fe}(\mathrm{III})_{3^{-}}$ $(\mathrm{Cit})_{(4-\mathrm{x})}-(\mathrm{Mal})_{\mathrm{x}}$ (with $\mathrm{x}$ ranging from 1 to 3 ). The absence of the $\mathrm{Fe}(\mathrm{III})_{3}-\mathrm{O}-(\mathrm{Cit})_{3}$ complex and $\mathrm{Fe}(\mathrm{III})_{3}-(\mathrm{Cit})_{3}$ complex in the pea samples despite the presence of citric acid would confirm a higher stability for the mixed iron complexes $\mathrm{Fe}(\mathrm{III})_{3}-(\mathrm{Cit})_{(4-\mathrm{x})}-(\mathrm{Mal})_{\mathrm{x}}$ $\left(\mathrm{x}=1\right.$ to 3 ) compared the ' $\mathrm{Fe}(\mathrm{III})_{3}-\mathrm{O}-(\mathrm{Cit})_{3}$ ' complex or $\mathrm{Fe}(\mathrm{III})_{3}-(\mathrm{Cit})_{3}$ complex as it was also observed with the standard mixture [20].

Concerning $\mathrm{Fe}(\mathrm{II})$, it was found to bind at trace level citrate, malate and aspartate as $\mathrm{Fe}(\mathrm{III})$ but only $\mathrm{Fe}(\mathrm{II})$ and not $\mathrm{Fe}(\mathrm{III})$ was found to be complexed by nicotianamine [16]. The signal-to-noise ratio found in HILIC of xylem sap samples with total Fe concentrations of approximately $40 \mu \mathrm{M}$ were 12 and 6 in HPLC-ESI-TOFMS and HPLC-ICP-MS, respectively. Therefore, in plant saps with Fe:Cit ratios favoring the formation of $\mathrm{Fe}_{3} \mathrm{Cit}_{3}$, an iron Fe concentration of approximately $25-30 \mu \mathrm{M}$ would be needed for the $\mathrm{Fe}_{3} \mathrm{Cit}_{3}$ complex to be detected [20].

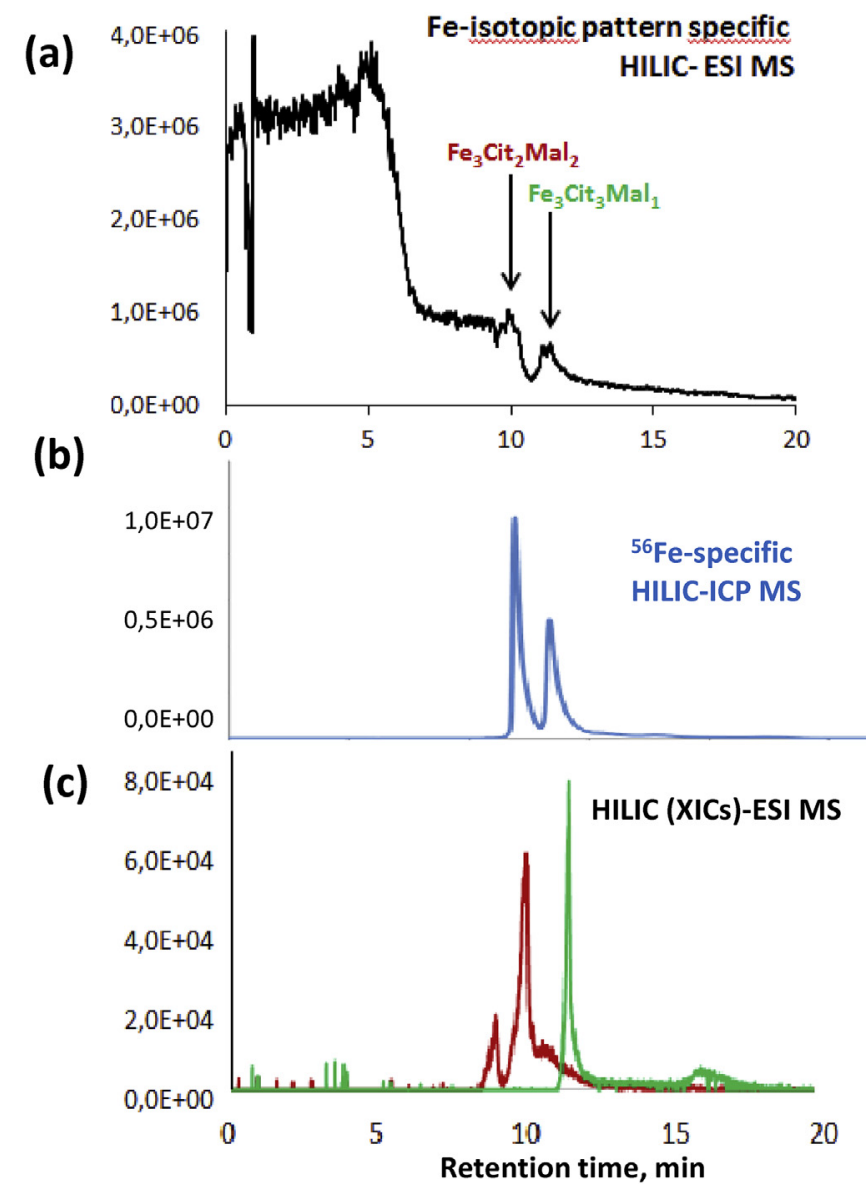

Fig. 5. A comparison of (a) the automatic data mining (Compound Discoverer ${ }^{\mathrm{TM}}$, ThermoFisher Scienfic) using two iron isotopes $\left({ }^{56} \mathrm{Fe}\right.$ and $\left.{ }^{57} \mathrm{Fe}\right)$, mass tolerance: $5 \mathrm{ppm}$, intensity tolerance: $20 \%$, (b) ICP MS detection $\left({ }^{56} \mathrm{Fe}\right.$ ) and confirmed by (c) XICs of mixed citrate-malate iron complexes for a standard solution $(100 \mathrm{ppb}$ as Fe at $\mathrm{pH} 5.5$, molar ratio Fe:Ma:Cit $=1: 25: 5)$. 


\subsubsection{Capillary zone electrophoresis (CZE)}

The separation efficiency of CE measured in terms of the number of theoretical plates $(50,000-100,000)$ exceeds by a factor of 30-50 that of HILIC, and by far more that of SEC and the analysis of nanoliter sample volumes is possible. Three phytosiderophores (mugineic acid, epi-mugineic acid and deoxymugineic acid) and their ferric model complexes were analyzed using CE-ESI MS and CE-ICP MS, the latter method was reported to be quantitative but no application to real samples was shown [43]. It has to be stated that a continuous interest and expectations raised by CZE techniques for the two decades are still largely not fulfilled, apparently because of the difficulties with the stability of metal complexes in high electric fields and because of the poor robustness of the system.

\subsubsection{ICP MS vs. electrospray MS detection in chromatography}

ICP MS offers the possibility of multi-element detection, including that of $\mathrm{S}$ and $\mathrm{P}$ which gives useful hints to the putative identity of the complexes present. For example, the Fe-phytate complex was tentatively identified on the basis of co-elution with phosphorous and the decrease of iron and phosphorous signals following a treatment with phytase [7]. The $\mathrm{Fe}_{4}\left(\mathrm{IP}_{6}\right)_{18}$ stoichiometry was proposed based on the $\mathrm{Fe} / \mathrm{P}$ ratio in a further purified complex [7]. The identification in SEC based on the co-elution with other elements and on the retention time matching with standards is rather tricky as the chromatographic purity of the chromatographic signals can hardly be guaranteed.

The intensity of the iron signal is independent of the coordination environment and was considered as a measure of the quantitative distribution of iron [2]. This can be misleading for two reasons: the recovery of the individual fractions is seldom verified (ideally the fraction should be collected and re-injected) and the purity of the chromatographic purity of the peaks is poor.

The high resolution of state-of-the-art ESI MS together with high mass accuracy allow for automatic data mining in search for iron species based on its isotopic pattern and species mass defects. A good agreement was obtained for a study of standard mixture of citrate-malate iron complexes between the automatically found and ICP MS detected iron species (Fig. 5).

\subsection{Validation of iron speciation data}

Dynamic metal-ligand systems include inevitably labile or transient metal species and direct spectroscopic methods are ideally needed to study their equilibria. Even for relatively stable species ligand exchange reactions may occur in the presence of competing ligands and/or redox mediators. The formation of artifact Fe species which are not those actually present in the original
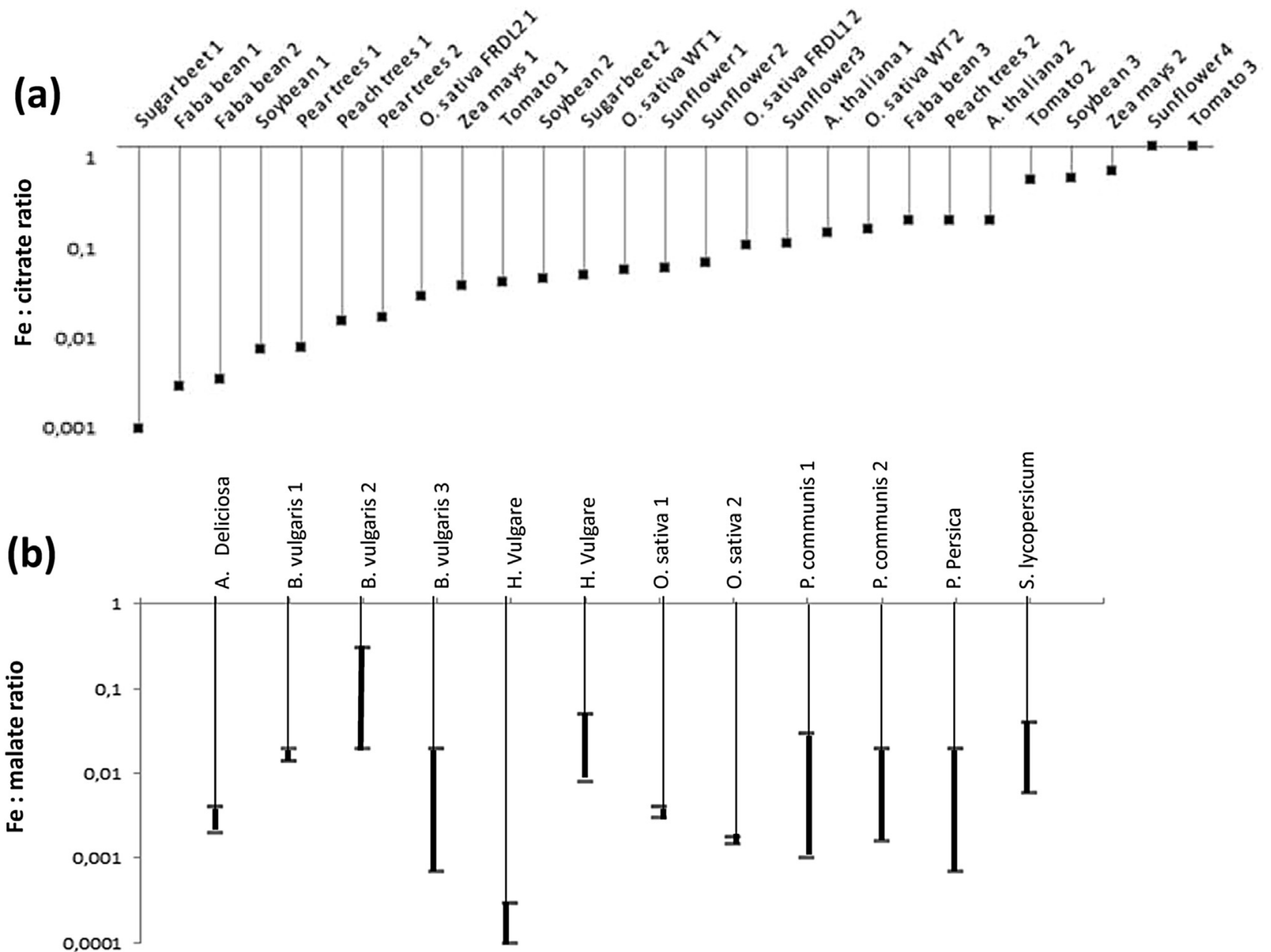

Fig. 6. Fe:citrate (a) and Fe:malate (b) ratios in plant sap samples reported in the literature (compiled from Refs. [20] and [18]). 
sample may occur. Due to this specificity, the direct application of criteria for confidence levels defined and accepted in the general metabolomics community is not viable [44]. For example, for iron chelates the possibility of redox-mediated ligand exchange of the phytosiderophore 2'-deoxymugineic acid against nicotianamine [45] and direct ligand exchange of nicotianamine against citrate [46] were demonstrated.

The minimum requirements for the validation of iron-speciation data include:

(i) use of at least two different chromatographic separation mechanisms to confirm the presence of a given species. Indeed, direct large-scale detection and identification of metal complexes in plant fluids by SEC and HILIC with dual elemental and molecular mass spectrometric detection revealed the presence of a series of species in pea fluids including xylem or liquid endosperm [16]. However, out of seven iron complexes detected by HILIC-ICP/ESI MS, only three of them were confirmed to be present by a complementary SEC-ICP/ESI MS [16],

(ii) confirm the presence of ligand by on-line post column acidification at the retention time of the iron complex, different from that of the free ligand. The presence of malic and citric acids at the elution volumes of the iron complexes whereas the free citric and malic acids present in the sample eluted much later so the hypothesis of in-source formation of complexes could be discarded [16],

(iii) optimize electrospray ionization conditions for the standards complexes to avoid in-source fragmentation [20],

(iv) confirm the presence of iron in the complex detected by ESI MS by the isotopic pattern or accurate mass. The observation of the iron-characteristic isotopic pattern is difficult due to the high 15.7 intensity ratio between the first $\left({ }^{56} \mathrm{Fe}-91.5 \%\right)$ and the second $\left({ }^{54} \mathrm{Fe} 5.85 \%\right)$ most abundant isotopes. The results obtained for natural and isotopically labeled $\left({ }^{54} \mathrm{Fe}\right)$ species were obtained in parallel in order to confirm the identity of Fe-citrate complexes [20]. ICP MS co-elution and fortification of the species isotopic pattern were proposed to as additional means of species recognition [20],

(v) confirm the identity of the molecular structures of Fe complexes by tandem MS [16]. For example, the major species identified in the tomato sap - $\mathrm{Fe}(\mathrm{III})_{3}-\mathrm{O}-(\mathrm{Cit})_{3}$ complex [20] has the same molecular mass as the $\mathrm{Fe}(\mathrm{III})_{3}-(\mathrm{Cit})_{1}$-(Mal $)_{3}$ one $[16,17]$. In the absence of MS/MS, a wrong assignment of the complex identities cannot be excluded, especially that malic acid is sometimes found in higher proportion than citrate in

(a)
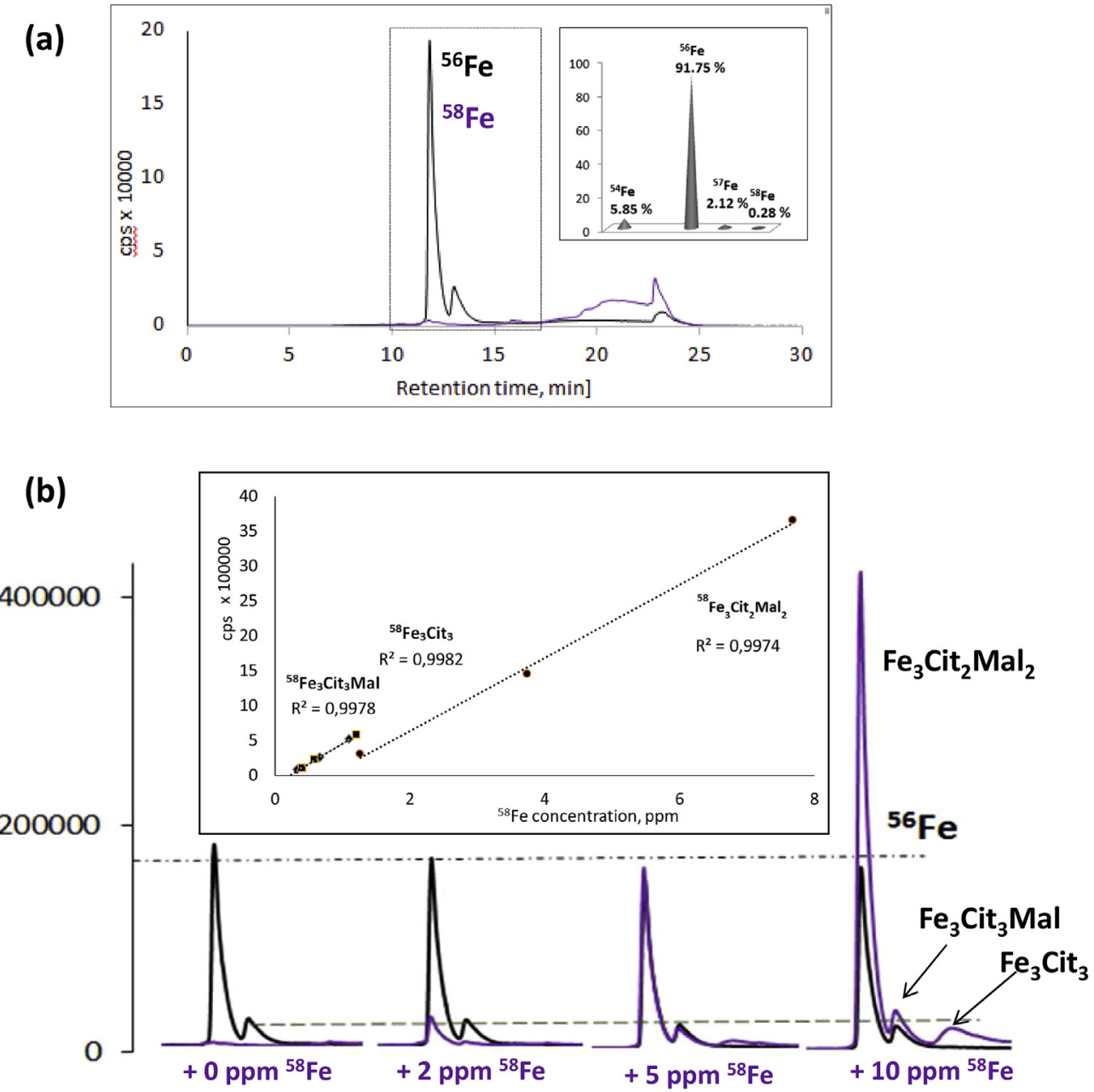

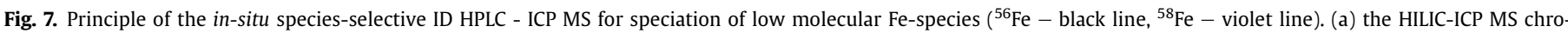

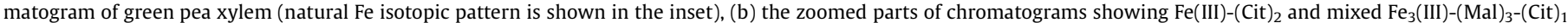

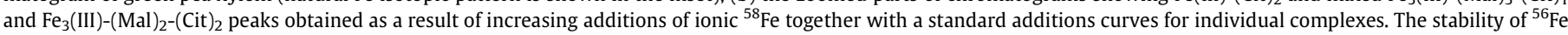
peaks is shown by dashed lines. 
plant shoots and its concentration can increase in the case of Fe deficiency $[28,41,47]$.

\subsection{Quantification techniques in Fe speciation analysis}

\subsubsection{Column recoveries and external calibration}

The quantification of Fe complexes with organic ligands is hindered by species lability and ionization differences in ESI MS. The column recoveries are typically at the $60-70 \%$ level $[16,20]$. Quantification on the basis of an external calibration curve is hardly feasible. The method of standard addition of iron complexes to samples is not possible either - it leads to disturbance of complexation equilibria (e.g., addition of Fe-citrate to the mixture of citrate-malate changes the initial ratio of peaks). A broad iron peak, tentatively assigned to Fe-oxyhydroxide [20], was observed at unusually long retention time and considered as a possible artifact.

\subsubsection{Pre-column species-specific and post-column species unspecific isotope dilution}

Iron has 4 natural isotopes: ${ }^{54} \mathrm{Fe},{ }^{56} \mathrm{Fe},{ }^{57} \mathrm{Fe}$ and ${ }^{58} \mathrm{Fe}$ with natural relative abundance of $5.85,91.75,2.12$ and $0.28 \%$, respectively, which opens multiple possibilities to isotope dilution quantification.

Specific Fe-containing molecules can be quantified by isotope dilution provided that enriched iron-labeled standards are available and that iron is not exchanged with other ligands present in the sample. These prerequisites were fulfilled for ferritin, a protein considered as an important source of bioavailable iron [48,49], of which the quantification - rather than the determination of the total iron - is of interest for food chemists [50,51]. For this purpose, a recombinant $\left[{ }^{57} \mathrm{Fe}\right]$-labeled bean ferritin was produced, mixed with a sample, and purified by ion exchange chromatography [6] prior to TIMS. The concept can be potentially carried out in the on-line format as demonstrated elsewhere by anion exchange chromatography - ID ICP MS determination of iron transferrin in human serum [52].

Post-column unspecific isotopic dilution quantification was carried out by continuously adding ${ }^{57} \mathrm{Fe}$ in EDTA between the exit of the column and the ICP MS nebulizer. The HILIC-ICP-MS intensity chromatograms were converted into Fe molar flow chromatograms using the isotope pattern deconvolution (IPD) equations. Accurate isotope abundances of the isotopically enriched solutions were determined by direct ICP-MS injections and used for the calculations of eluted Fe-citrate complex in tomato plant xylem [20]. Note, that in contrast to pre-column isotope dilution, the post-column isotope dilution allows no correction for the incomplete recovery.

\subsubsection{Isotope dilution HPLC-ICP MS after in-situ formation of the calibration standard}

Plant fluids contain considerable excess of free ligands (citrate or malonate, Fig. 6) which opens the possibility of the in-situ formation of isotopically labeled species of iron as a result of the addition of ionic Fe isotope to a sample. The prerequisite is the complete reaction of the added spike which can be readily verified by HPLC-ICP MS. This method allows the correction for on-column dissociation or changes in speciation during chromatography. A proof-of-principle of this novel procedure (summarized in Fig. 7) has been tested for the quantification of iron citrate-malonate complexes in embryo sac liquid of Pisum sativum. The additions of ionic solution of ${ }^{58} \mathrm{Fe}$ resulted in the formation (violet trace in Fig. $7 \mathrm{~b}$ ) of the same (but ${ }^{58} \mathrm{Fe}-$ labeled) complexes as those present in the original sample (Fig. 7a). The originally present species are not affected by the isotope addition the original speciation of ${ }^{56} \mathrm{Fe}$ (black trace) remained unchanged despite the ${ }^{58} \mathrm{Fe}$ additions. Consequently, it was possible to establish a calibration curve to serve for the quantification (insert in Fig. 7b). A complementary model study carried out with standards showed that identical species distribution was obtained by the addition of ionic ${ }^{58} \mathrm{Fe}$ and mixing ${ }^{56} \mathrm{Fe}$ and ${ }^{58} \mathrm{Fe}$ complexes.

\section{Conclusions and perspectives}

Dual separation mechanisms (SEC and HILIC) HPLC with dual ICP MS and ESI MS detection offer the most accomplished, at present, tool for a comprehensive speciation of low molecular weight iron complexes in micro- or nanoliter volumes of plant fluids. The increasing sensitivity and robustness of electrospray high resolution high mass accuracy MS and the progress in software for data deconvolution for element specific analysis are responsible for the progressive replacement of ICP MS detection by ESI MS detection in chromatography for iron speciation studies. As ESI MS is a concentration specific detector, the natural trend seems to be the miniaturization of sample introduction using on-chip HPLC allowing the analysis of picoliter volumes of intracellular fluids. The isotopic specificity of mass spectrometric techniques spurs the use of stable iron isotopes for studies of the complex stability, exchange kinetics and the isotope dilution for quantification. In contrast to metabolites, the full characterization of iron-binding proteins seems to be a distant goal because of the lack of efficient separation techniques and by far less sensitive detection by ESI MS. There does not really seem to be really an alternative for HPLC - MS for speciation of iron at ppb concentration levels in complex samples. However, once novel species are identified, the standards can be produced and their contribution to speciation should be evaluated by X-ray absorption spectroscopy. Spectra comparisons between the sample, extracts and chromatographic fractions can allow the detection of risk of changes in speciation. The potential of X-ray absorption spectroscopy is expected to grow with the use of higher brilliance sources, larger spectrum of standards taken into account during computing and better fitting algorithms.

\section{References}

[1] World Health Organization, C.f.D.C.a, Prevention, Assessing the Iron Status of Populations, World Health Organization, Geneva, 2007.

[2] R.K. Gupta, S.S. Gangoliya, N.K. Singh, J. Food Sci. Technol. 52 (2015) 676.

[3] Y.F. Xue, T. Eagling, J. He, C.Q. Zou, S.P. McGrath, P.R. Shewry, F.J. Zhao, J. Agric. Food Chem. 62 (2014) 4738.

[4] T. Eagling, A.L. Neal, S.P. McGrath, S. Fairweather-Tait, P.R. Shewry, F.J. Zhao, J. Agric. Food Chem. 62 (2014) 708.

[5] T. Eagling, A.A. Wawer, P.R. Shewry, F.J. Zhao, S.J. Fairweather-Tait, J. Agric. Food Chem. 62 (2014) 10320.

[6] M. Hoppler, I. Egli, N. Petry, D. Gille, C. Zeder, T. Walczyk, M.W. Blair, R.F. Hurrell, J. Food Sci. 79 (2014) C1629.

[7] D.P. Persson, T.H. Hansen, K.H. Laursen, J.K. Schjoerring, S. Husted, Metallomics 1 (2009) 418.

[8] T. Kobayashi, N.K. Nishizawa, Iron Uptake, Translocation, and Regulation in Higher Plants, 2012, p. 131.

[9] J. Morrissey, M.L. Guerinot, Chem. Rev. 109 (2009) 4553.

[10] S. Clemens, M. Weber, Plant Signal Behav 11 (2016) e1114197.

[11] P. Sisó-Terraza, A. Luis-Villarroya, P. Fourcroy, J.-F. Briat, A. Abadía, F. Gaymard, J. Abadía, A. Álvarez-Fernández, Front Plant Sci 7 (2016).

[12] P. Mladenka, K. Macakova, L. Zatloukalova, Z. Rehakova, B.K. Singh, A.K. Prasad, V.S. Parmar, L. Jahodar, R. Hrdina, L. Saso, Biochimie 92 (2010) 1108.

[13] L. Guo, T.J. Cutright, Int. J. Phytoremediation 19 (2017) 254.

[14] F.R. Segura, E.A. Nunes, F.P. Paniz, A.C.C. Paulelli, G.B. Rodrigues, G.Ú.L. Braga, W. dos Reis Pedreira Filho, F. Barbosa, G. Cerchiaro, F.F. Silva, B.L. Batista, Environ. Pollut. 218 (2016) 813.

[15] F.-J. Zhao, S.P. McGrath, Curr. Opin. Plant Biol. 12 (2009) 373.

[16] P. Flis, L. Ouerdane, L. Grillet, C. Curie, S. Mari, R. Lobinski, New Phytol. 211 (2016) 1129.

[17] L. Grillet, L. Ouerdane, P. Flis, M.T.T. Hoang, M.P. Isaure, R. Lobinski, C. Curie, S. Mari, J. Biol. Chem. 289 (2014) 2515.

[18] A. Álvarez-Fernández, P. Díaz-Benito, A. Abadía, A.-F. López-Millán, J. Abadía, Front. Plant Sci. 5 (2014) 105.

[19] C. Krüger, O. Berkowitz, U.W. Stephan, R. Hell, J. Biol. Chem. 277 (2002) 25062. 
[20] R. Rellán-Álvarez, J. Giner-Martínez-Sierra, J. Orduna, I. Orera, J.A. RodríguezCastrilln, J.I. García-Alonso, J. Abadía, A. Alvarez-Fernández, Plant Cell Physiol. 51 (2010) 31.

[21] S.P. Singh, K. Vogel-Mikuš, I. Arčon, P. Vavpetič, L. Jeromel, P. Pelicon, J. Kumar, R. Tuli, J. Exp. Bot. 64 (2013) 3249.

[22] E. Lombi, K.G. Scheckel, I.M. Kempson, Environ. Exp. Bot. 72 (2011) 3.

[23] R. Terzano, T. Mimmo, B. Vekemans, L. Vincze, G. Falkenberg, N. Tomasi, M. Schnell Ramos, R. Pinton, S. Cesco, Anal. Bioanal. Chem. 405 (2013) 5411.

[24] N. De Brier, S.V. Gomand, E. Donner, D. Paterson, E. Smolders, J.A. Delcour, E. Lombi, Plant, Cell Environ. 39 (2016) 1835.

[25] A.L. Neal, K. Geraki, S. Borg, P. Quinn, J.F. Mosselmans, H. Brinch-Pedersen, P.R. Shewry, J. Biol. Inorg. Chem. 18 (2013) 557.

[26] S. Lee, U.S. Jeon, S.J. Lee, Y.K. Kim, D.P. Persson, S. Husted, J.K. Schjorring, Y. Kakei, H. Masuda, N.K. Nishizawa, G. An, Proc. Natl. Acad. Sci. U. S. A. 106 (2009) 22014.

[27] E. Yoshimura, S. Sakaguchi, H. Nakanishi, N.K. Nishizawa, I. Nakai, S. Mori, Phytochem. Anal. 11 (2000) 160.

[28] A.F. López-Millán, F. Morales, Y. Gogorcena, A. Abadía, J. Abadía, J. Plant Physiol. 166 (2009) 375.

[29] R. Nishiyama, M. Kato, S. Nagata, S. Yanagisawa, T. Yoneyama, Plant Cell Physiol. 53 (2012) 381.

[30] T. Hirayama, H. Nagasawa, J Clin Biochem Nutr 60 (2017) 39.

[31] T. Ariga, K. Hazama, S. Yanagisawa, T. Yoneyama, Soil Sci. Plant Nutr. 60 (2014) 460.

[32] L. Ouerdane, S. Mari, P. Czernic, M. Lebrun, R. Łobiński, J. Anal. Atomic Spectrom. 21 (2006) 676

[33] J. Szpunar, Analyst 125 (2000) 963.

[34] B. Buszewski, S. Noga, Anal. Bioanal. Chem. 402 (2012) 231.

[35] J. Köster, R. Shi, N. Von Wirén, G. Weber, J. Chromatogr. A 1218 (2011) 4934.
[36] L. Nováková, L. Havlíková, H. Vlčková, TrAC - Trends Anal. Chem. 63 (2014) 55.

[37] K. Spagou, H. Tsoukali, N. Raikos, H. Gika, I.D. Wilson, G. Theodoridis, J. Sep. Sci. 33 (2010) 716.

[38] R. Rellán-Álvarez, S. López-Gomollón, J. Abadía, A. Álvarez-Fernández, J Agric Food Chem 59 (2011) 6864

[39] M. Dell'mour, W. Schenkeveld, E. Oburger, L. Fischer, S. Kraemer, M. Puschenreiter, M. Lämmerhofer, G. Koellensperger, S. Hann, Electrophoresis 33 (2012) 726 .

[40] M. Tsednee, Y.W. Mak, Y.R. Chen, K.C. Yeh, New Phytol. 195 (2012) 951.

[41] N. Jelali, M. Wissal, M. Dell'orto, C. Abdelly, M. Gharsalli, G. Zocchi, Environ Exp Bot 68 (2010) 238.

[42] Y. Xuan, E.B. Scheuermann, A.R. Meda, H. Hayen, N. von Wirén, G. Weber, ] Chromatogr A 1136 (2006) 73.

[43] M. Dell'mour, G. Koellensperger, J.P. Quirino, P.R. Haddad, C. Stanetty, E. Oburger, E. Puschenreiter, S. Hann, Electrophoresis 31 (2010) 1201.

[44] J.C. May, J.A. McLean, Advanced Multidimensional Separations in Mass Spectrometry: Navigating the Big Data Deluge, 2016, p. 387.

[45] G. Weber, N. von Wirén, H. Hayen, BioMetals 21 (2008) 503.

[46] R. Rellán-Álvarez, J. Abadía, A. Álvarez-Fernández, Rapid Commun. Mass Spectrom. 22 (2008) 1553.

[47] G. Lattanzio, S. Andaluz, A. Matros, J.J. Calvete, J. Kehr, A. Abadía, J. Abadía, A.F. López-Millán, Proteomics 13 (2013) 2283.

48] B. Lonnerdal, Int. J. Vitam. Nutr. Res. 77 (2007) 152

[49] C. Lv, G. Zhao, B. Lonnerdal, J. Nutr. Biochem. 26 (2015) 532.

[50] R.J. Lukac, M.R. Aluru, M.B. Reddy, J. Agric. Food Chem. 57 (2009) 2155.

[51] G. Drakakaki, S. Marcel, R.P. Glahn, E.K. Lund, S. Pariagh, R. Fischer, P. Christou, E. Stoger, Plant Mol. Biol. 59 (2006) 869.

[52] M.E. Del Castillo Busto, M. Montes-Bayón, A. Sanz-Medel, Anal. Chem. 78 (2006) 8218. 